\title{
AS TENDÊNCIAS RESTRITIVAS DA LEGITIMAÇÃO DE AGIR NO PROCESSO COLETIVO E SEUS IMPACTOS NA SISTEMATIZAÇÃO DE UM CÓDIGO PROCESSUAL COLETIVO BRASILEIRO DEMOCRATIZADO.
}

Resumo: O objetivo da pesquisa é apresentar proposições teóricas que evidenciem a necessidade de codificação do processo coletivo brasileiro nos moldes democráticoparticipativos trazidos pelo texto constitucional vigente. A escolha do tema se justifica na necessidade de reconhecer o direito de todos os interessados difusos e coletivos poderem participar igualmente da construção do provimento final de mérito. Por meio da pesquisa bibliográfica e documental concluiu-se criticamente que o atual modelo de processo coletivo é autocrático-representativo e precisa ser ressignificado sob a ótica do sistema participativo previsto na Constituição brasileira de 1988.

Palavras-chave: Processo coletivo; Legitimidade processual; Codificação; Sistema participativo; Processo democrático.

\section{THE RESTRICTIVE TRENDS IN THE LEGITIMATION TO ACT IN THE COLLECTIVE PROCESS AND ITS IMPACTS ON THE SYSTEMATIZATION OF A DEMOCRATIZED BRAZILIAN COLLECTIVE PROCEDURE CODE.}

\begin{abstract}
The objective of the research is to present theoretical propositions that highlight the need for codification of the Brazilian collective process in the democratic-participatory molds brought by the current constitutional text. The choice of theme is justified by the need to recognize the right of all diffuse and collective stakeholders to participate equally in the construction of the final award of merit. Through bibliographical and documentary research, it was critically concluded that the current model of collective process is autocraticrepresentative and needs to be re-signified from the perspective of the participatory system provided for in the Brazilian Constitution of 1988.
\end{abstract}

Keywords: Collective process; Procedural legitimacy; Codification; Participatory system; Democratic process.

\footnotetext{
${ }^{1}$ Professor do Programa de Pós-Graduação Stricto Sensu em Proteção dos Direitos Fundamentais da Universidade de Itaúna (Doutorado e Mestrado). Pós-doutorado em Educação (UFMG) e Psicologia (PUCMINAS). Doutorado e Mestrado em Direito Processual (PUCMINAS). Bacharel em Direito pela Universidade Federal de Uberlândia. E-mail: fvcufu@uol.com.br

${ }_{2}$ Mestranda em Proteção dos Direitos Fundamentais pela Universidade de Itaúna. Advogada e Professora Universitária. E-mail: talitabrazz@yahoo.com
} 


\section{Introduçãa}

O objetivo geral da pesquisa é analisar a legitimação da processualística coletiva, na qual é fundada em uma ciência individualista, já que sua procedimentalização se regula a partir do Código de Processo Civil, com a finalidade de demonstrar o quanto essa restrição traz impactos na sistematização de um modelo único de processo coletivo no Brasil. Pretendese demonstrar na presente pesquisa como premissas teóricas do processo civil brasileiro vigente obstaculizam a construção da autonomia científica do processo coletivo democrático.

A escolha do tema se justifica em razão da relevância teórico-jurídica, pela gama de debates existentes, visto que este é um tema caro ao processo brasileiro a partir da perspectiva de um modelo constitucionalizado de processo. A codificação de um sistema único das tutelas coletivas é um meio para que se alcance o fiel objeto da demanda em conceder aos interessados difusos e coletivos a garantia de uma jurisdição segura na qual poderão de fato obter um ambiente jurídico-normativo condizente com a pretensão aduzida em juízo.

Inicialmente foi desenvolvido um estudo teórico sobre o sistema representativo levando ao debate da problemática da legitimidade processual nas demandas coletivas a partir da análise das fases de coletivização do direito processual brasileiro.

No entanto, o modelo de processo coletivo proposto pelo legislador constituinte é fundado no sistema participativo, ou seja, os destinatários do provimento final de mérito possuem o direito de participarem diretamente da sua construção, requisito essencial para a legitimidade democrática da decisão judicial. A partir disso, fora analisado a legitimidade processual nas demandas coletivas sob a perspectiva da ação civil pública e da ação popular.

Nesse sentido, o ordenamento jurídico brasileiro, de forma tênue, editou leis referentes aos direitos coletivos, difusos e individuais homogêneos, inclusive a reforma do próprio Código de Processo Civil, dando a este um cunho constitucionalista. Essas análises se sustentam e a pesquisa anota seus estudos, pontuando as características do microssistema de processo coletivo, bem como os movimentos e anteprojetos de codificação do direito processual coletivo no Brasil. Por conseguinte, a pesquisa chega ao ponto crucial que buscará concluir acerca da real necessidade de codificação das ações coletivas.

Visando recortar o tema aqui exposto, propõe-se a seguinte pergunta-problema: tendências restritivas da legitimação de agir nas ações coletivas, concorrem para a não elaboração de um Código de Processo Coletivo Brasileiro democratizado? 
Por meio da pesquisa bibliográfica e documental foi possível demonstrar que o sistema representativo de processo coletivo brasileiro, adotado a partir dos princípios individuais do processo civil, reproduz um modelo de jurisdição autocrática, por meio da qual o julgador constrói unilateralmente o provimento final de mérito sem permitir a participação direta dos destinatários finais.

O método dedutivo foi utilizado para delimitar o espectro analítico proposto, partindo-se de uma concepção macro analítica, qual seja, o modelo de processo coletivo democrático-participativo, recortando-se a análise no estudo específico da legitimação da ação civil pública e ação popular como modelos norteadores de processo coletivo. A construção de análises temáticas, teóricas, interpretativas e comparativas tornou viável o estudo crítico do tema proposto.

\section{O sistema representativo e a problemática da legitimidade processual nas demandas} coletivas a partir da análise das fases de coletivização do direito processual brasileiro.

O caráter tradicional do direito processual é fundado em uma ciência individualista, na qual sua procedimentalização se regula através do Código de Processo Civil, sob o viés autor-réu. Nesse sentido, o ordenamento jurídico brasileiro, de forma tênue, editou leis referentes aos direitos coletivos, difusos e individuais homogêneos, inclusive a reforma do próprio Código de Processo Civil, dando a este um cunho constitucionalista.

Os três grandes atos de coletivização do processo no Brasil, "foi a edição da Lei $\mathrm{n}^{\circ}$ 7347/85 (Lei da Ação Civil Pública), a Constituição de 1988, que garante a defesa de direitos e garantias fundamentais individuais e coletivos e a edição da Lei $n^{\circ}$ 8078/90, o Código de Defesa do Consumidor" (ALMEIDA, 2007, p.18). A historicidade das ações coletivas está alçada na manifesta necessidade de proteção a bens não individualizados, ou seja, bens de interesse coletivo e social.

É importante ressaltar o caráter histórico do processo coletivo no Brasil, "posto que é de fundamental importância estudar o desenvolvimento do processo coletivo, a defesa de direitos transindividuais, a autonomia do direito processual e a fase de instrumentalização do processo" (ALMEIDA, 2007, p.18). A legislação processual brasileira é pautada em um viés privatista, na qual vem sendo questionada a partir dos princípios constitucionais, a fim de 
garantir um regime jurídico democrático no mérito das demandas coletivas. O que se verifica, de forma apriorística, é que o processo coletivo tem como fonte primária o processo civil, fato esse que desencadeia consequencias diretas na sistematização de sua autonomia cientifica.

O desenvolvimento do processo coletivo no Brasil se deu a partir da ação popular, que inicialmente foi inserida no direito pátrio na Constituição de 1934, em seu artigo 113, XXXVIII, que instutuía que qualquer cidadão seria parte legítima para pleitear a declaração de nulidade ou anulação de atos lesivos do patrimônio da União, Estados ou dos Municípios. Aqui destaca-se o controle das atividades estatais, no que pese ao cidadão ter o poderio sob o patrimônio público, ou seja, a efetivação da tutela aos princípios da administração pública, destacando-se a moralidade administrativa (ALMEIDA, 2007).

Após a Constituição de 1934, houve a supressão deste direito diante da publicação da Constituição de 1937, visto que o Brasil vivia sob um regime político de exceção e o cidadão foi afastado do rol de interessados ativos nas decisões estatais. Em adendo, tem-se que: "Diante do momento político vivenciado pelos brasileiros na década de 1930 - Ditadura Getulista - a ação popular foi suprimida da Constituição de 1937, retornando ao ordenamento jurídico brasileiro somente com a Constituição de 1946" (FERREIRA, 2017, p. 79). Observase aqui a perda do respaldo jurídico-democrático do Estado para com as questões sociais, visto que o povo tem interrompida a instrumentalidade reservada para a sua atuação direta com os bens de interesse coletivo.

Conforme mencionado, houve o renascimento da ação popular na Constituição de 1946, disciplinado no artigo 141, § 38 em que, a possibilidade jurídica do cidadão em ter o controle sob o patrimônio público é novamente disposta na legislação pátria. No ano de 1965, quando o Brasil se encontrava sob o período da ditadura militar, foi sancionada a Lei $\mathrm{n}^{\circ} 4.717$, a fim de disciplinar no plano infraconstitucional a ação popular, em que a titularidade de propositura é de qualquer cidadão. Existiam para tal demanda o requisito de comprovação de cidadania e de legitimitidade para propositura da ação, quais sejam: o título de eleitor e a demonstração de regularidade no exercício dos direitos políticos.

O objetivo do legislador esbarra na tentativa de institucionalizar o controle das atividades do Estado, de forma a integrar o cidadão no rol dos legitimados para proposição da ação popular. Assim, Fabricio Veiga Costa ressalta que: "Tal fiscalidade não era de natureza ampla, excluindo-se, por exemplo, a possibilidade de controle do meio ambiente e demais direitos de natureza metaindividual e potencializador do exercício pleno da cidadania” (2012, 
p.117). Tem-se, portanto, que nesse período não é possível afirmar que de fato fora garantido o exercício legítimo de propositura da ação popular pelo cidadão, pois o objeto se deu de forma restrita ao patrimônio público, excluindo-se o patrimonio histórico e cultural, meio ambiente, moralidade, ou seja, tutelava apenas poucos direitos difusos.

A Constituição de 1967, juntamente com a emenda constitucional $\mathrm{n}^{\circ} 1 / 69$, previu em seu artigo 153, § 31, que qualquer cidadão seria parte legítima para propor ação popular, que vise a anular atos lesivos ao patrimônio de entidades públicas. Observa-se, mais uma vez, uma legislação um tanto quanto restrita, na qual não se garante ao cidadão o efetivo exercício da cidadania através da propositura da ação em comento (ALMEIDA, 2007).

Já em 1981, adveio a Lei $n^{\circ}$ 6838/81, que instituiu a Política Nacional do Meio Ambiente, tutelando, assim, o meio ambiente, na qual fez surgir a ação civil pública, que previu a possibilidade de defesa de interesses difusos relacionados aos meio ambiente. Ou seja, observa-se que: “A legitimação do Ministério Público representou um avanço, pois somente o cidadão era legitimado para a propositura da ação popular, enquanto que no pólo passivo somente o poder público poderia figurar, com esta nova disciplina qualquer agente poluidor poderia ser demandado (CARVALHO, 2005, p. 223).

Nessa seara, o ano de 1985 foi o marco da consolidação do processo coletivo no Brasil, com o advento da Lei $\mathrm{n}^{\circ} 7347$, pela qual disciplinou a ação civil pública, ampliando os objetos da ação, quais sejam: meio ambiente, consumidor e patrimônio público. Assim, demonstra Fabrício Veiga Costa: “ Isso representa mais uma tentativa de o legislador pátrio regulamentar através de uma legislação específica o processo coletivo" (2012, p. 117).

A lei de ação civil pública é tida como o marco do processo coletivo brasileiro, sendo que nesses trinta e dois anos ocorreram conquistas, mas também foi marcada por retrocessos profundos. Destacam-se, portanto, como avanços, a Constituição Federal de 1988, o Código de Defesa do Consumidor, pela qual veio defender a situação da proteção individual, e, também, o Estatuto da Criança e do Adolescente, Estatuto do Idoso, Estatuto da Cidade, entre outros microssistemas jurídicos de proteção de direitos coletivos e difusos. Os retrocessos se limitam às medidas provisórias, que quando editadas tinham o fito de limitar a tutela coletiva.

Com o advento da Constituição de 1988, em seu artigo 5, LXXIII, o legislador reiterou a legitimidade de qualquer cidadão em participar do controle dos atos e das atividades estatais. Conforme bem explica José Emílio Medauar Omatti: “a ação popular visa proteger 
qualquer direito relacionado ao patrimônio público, moralidade administrativa, meio ambiente e o patrimônio histórico e cultural [...]” (2020, p. 255).

O texto constitucional concedeu aos direitos difusos e coletivos a condição de garantias fundamentais, por estarem elencados no rol das cláusulas pétreas, sendo, portanto, de caráter imaterial, indisponível e irrenunciável. Nesse sentido, temos que o legislador constituinte, ao garantir que o cidadão seja legitimado a propor ação coletiva, veio ao encontro do princípio da participação popular elencado no artigo $1^{\circ}$ da $\mathrm{CRFB} / 88$, que trouxe a soberania popular como fundamento do Estado Democrático de Direito.

Diante do que fora exposto, a partir das fases de coletivização do direito processual brasileiro, cumpre sobrelevar as nuances do processo coletivo sob o aspecto representativo, o que choca com a realidade do Estado Democrático de Direito.

A Constituição de 1988, mais precisamente em seu artigo $5^{\circ}, \mathrm{XXXV}$, denota com precisão a ideia de um processo coletivo constitucionalizado, já que é assegurada a participação de todos os interessados (difusos e coletivos), indistintamente. Diante disso, temse que: "O processo coletivo, como mecanismo de concretização da democracia não atingirá o seu real alcance se não houver um aperfeiçoamento da técnica existente, que consequentemente conduzirá a uma reconstrução teórica” (FERREIRA, 2009, p. 54).

No entanto, o Brasil adota o sistema representativo, pelo qual se é observado através do rol taxativo de legitimados para a propositura das ações coletivas. Nesse aspecto, salienta Fabrício Veiga Costa: “O cidadão, além de não participar das discussões legislativas acerca da elaboração da legislação que implantará sistematicamente o processo coletivo no Brasil, é absolutamente excluído do rol de legitimados a propositura da ação coletiva" (2002, p. 129).

De outro modo, temos na CRFB/88 a soberania popular e a cidadania como principal modelo de efetivação do Estado Democrático de Direito, impondo de forma categórica a participação popular para a implementação de um sistema participativo, contrariando, assim, o sistema representativo vigente.

Nesse diapasão, ressalta-se aqui uma ponderação entre o sistema representativo, pelo qual se justifica na incapacidade do cidadão de atuar de forma isolada diante às questões que envolvam demandas coletivas e o reflexo do Estado Democrático de Direito trazido pela constitucionalização de direitos à cidadania plena, configurando a postulação participada das ações coletivas. 
3. Análise da legitimidade processual nas ações constitucionais: ação civil pública e ação popular.

A ação civil pública, disciplinada pela lei $\mathrm{n}^{\circ} 7347 / 85$, se consolidou com o advento da Constituição de 1988, elencado no artigo 129, III: "São funções institucionais do Ministério Público [...] promover o inquérito civil e a ação civil pública, para a proteção do patrimônio público e social, do meio ambiente e de outros interesses difusos e coletivos" (BRASIL, 1988).

A lei da ação civil pública dispõe de um rol taxativo dos legitimados ativos para sua propositura, quais sejam: o Ministério Público, a Defensoria Pública, a União, os Estados, o Distrito Federal e os Municípios, a autarquia, empresa pública, fundação ou sociedade de economia mista, bem como associações civis que sejam constuídas há mais de um ano e que, conste em seu estatuto o objetivo social de defesa daquele direito difuso a ser pleiteado.

Para tanto, é importante ressaltar a opção em readequar o sistema processual da tutela coletiva a partir da modificação dessa lei e seus legitimados, segundo Gomes Junior e Favreto (2010, p. 5): “A opção de readequar o Sistema Único Coletivo com a transformação da Lei da Ação Civil Pública em uma norma geral do sistema terá também outro relevante efeito prático: preparar o Ordenamento Jurídico para um futuro Código de Processo Coletivo".

Segundo leciona Juliana Maria Matos Ferreira: “A Lei da Ação Civil Pública institui a defesa em juízo de interessados difusos e coletivos por legitimados ativos que atuam em nome próprio na defesa da coletividade" (2017, p. 82). Tem-se aqui, uma atuação independente de cada legitimado, ou seja, a propositura de um, não influi de forma conjunta com os demais. De tal forma, é importante destacar, nesse momento, que dentre os legitimados, os cidadãos não foram incluídos pelo legislador.

Como bem elucida Juliana Maria Matos Ferreira: “Ao instituir o Estado Democrático de Direito, constitui uma nova ordem para discussão das funções do Estado e dos mecanismos de participação popular" (2017, p. 85). É de saber notório que a proteção dos direitos fundamentais é, de fato, a principal causa de efetivação da cidadania.

Destarte, nota-se que tais disposições rompem com os conceitos autoritários, de forma a ampliar e garantir na nova ordem constitucional a participação da sociedade de forma ampla diante do direito processual. Destaca-se, porém, o inciso I, do artigo $1^{\circ}$ do texto 
constitucional vigente, que denota a soberania popular e o parágrafo único do mesmo, na qual demonstra a preocupação do legislador constituinte em trazer o cidadão para a participação direta das decisões.

Ainda no texto constitucional de 1988, em seu artigo 5, XXXV, temos: "A lei não excluirá da apreciação do Poder Judiciário lesão ou ameaça a direito" (BRASIL, 1988). Observa-se, portanto, que o legislador constituinte, manifestadamente, elencou a possibilidade de normas de caráter proibitivo, fazendo com que o cidadão não tenha impedido seu direito de atuar diretamente em suas demandas junto ao poder Judiciário.

Deste modo, Juliana Maria Matos Ferreira: “Assim, verificamos que não há uma delimitação para a defesa de lesão ou ameaça de lesão apenas aos direitos individuais. Se a Constituição não efetuou tal limitação, não deverá a legislação infraconstitucional fazê-la" (2017, p. 88). Ademais, ao observarmos o modelo legislativo adotado pelo Brasil, no que atine o direito coletivo, afasta a manifestação dos indivíduos (coletividade), pois as decisoes judiciais proferidas no âmbito das ações coletivas não asseguram a formação participada do mérito processual, denotando o distanciamento do cidadão do rol de legitimados ativos da ação civil pública.

Para um maior esclarecimento sobre este tema, insta ponderar a percepção da adoção do sistema representativo nos estudos aqui realizados, sob o ponto de vista da Escola Paulista de Processo e a tentativa de elaboração de um Código Brasileiro de Processo Coletivo. Isto porque, as matérias abordadas nos anteprojetos propostos, tem como objeto primordial a extensão do rol dos legitimados para a propositura das ações coletivas, em especial a ação civil pública.

De certo que a influência instrumentalista na elaboração do Código de Processo Civil, na qual sua elaboração se tangencia em um procedimento de pretensões individuais, corrobora para que o processo coletivo se afaste de um sistema cuja participação no mérito seja de fato materializada no exercício democrático da cidadania.

A Lei da ação popular entrou em nosso ordenamento na Constituição de 1934, e se mantém ainda hoje, com um único intervalo, na vigência da Constituição de 1937, quando o Brasil era governado pelo Estado Novo. Em sua obra, Processo Coletivo - Tutela de Direitos Coletivos e Tutela Coletiva de Direitos, Teori Albino Zavascki, expõe que: "O que caracteriza a ação popular, desde as suas mais remotas origens romanas, é o exercício da ação por qualquer membro da coletividade, com maior ou menor amplitude, para a defesa de interesses 
coletivos" (2017, p. 85).

Na Constituição de 1988, no artigo 1º, parágrafo único, temos que: “Todo o poder emana do povo, que o exerce por meio de representantes eleitos ou diretamente, nos termos desta Constituição" (BRASIL,1988), redação pela qual permite afirmar que o texto constitucional, acompanha a lei infraconstitucional, no sentido de contribuir para o pleno exercício do Estado Democrático de Direito, como se observa na dada redação.

Contudo, "justifica-se, assim, a inclusão da lei da ação popular como primeira a delinear os direitos coletivos no Brasil, principalmente por incluir o cidadão como legitimado" (FERREIRA, 2017, p. 78). A ação popular pode ser conceituada como um instrumento constitucional quanto aos atos administrativos em geral, pela qual o cidadão se respalda na garantia de fiscalizar a idoneidade de seu governo, sendo, portanto um mecanismo fundamental para a participação popular.

Isto porque, mesmo o Brasil tendo optado no plano infraconstitucional pelo sistema representativo, ou seja, democracia indireta, este mesmo sistema possibilita que o cidadão participe diretamente dos atos da administração pública. A Lei no 4717/65, na qual disciplina a ação popular, ainda que instituída anterior à Constituição de 1988, deixa explícita a legitimidade de qualquer cidadão pleitear anulação ou declaração de nulidade aos atos lesivos ao patrimônio público, de modo a conferir aos cidadãos a participação na vida política.

Nesse sentido, nota-se que a legitimidade ativa desta ação é o cidadão. Tanto no texto constitucional, quanto no infraconstitucional, observa-se a máxima garantia de legitimação ao cidadão, de forma direta, resguardando o direito de exercer a função de fiscalizar, que em regra, é feita pelos representantes eleitos nas casas legislativas. Importante destacar que a ação popular é uma garantia coletiva, pois por meio dela o cidadão invoca a atividade jurisdicional, na intenção de proteger a coisa pública, configurando o interesse coletivo e não pessoal. Nas palavras de José Afonso da Silva, tem-se: "Mas ela é também uma ação judicial, porquanto consiste num meio ação de nulidade de invocar a atividade jurisdicional visando à correção de ato lesivo [...]. Sua finalidade é, pois, corretiva, não propriamente preventiva" (2011, p. 210).

Cumpre sobrelevar aqui o significado desta legitimidade, em que pese ser cidadão aquele que esteja no exercício de seus direitos civis e políticos, ou seja, o indivíduo deve possuir a qualidade de eleitor; para isso é necessário que este esteja em pleno gozo dos seus 
direitos políticos.

Os interesses tutelados pela ação popular, em seu caráter transindividual, evidenciado no texto constitucional de 1988, são ampliados, ou seja, não apenas quanto ao objeto da ação, a qual visa proteger o meio ambiente, seu patrimônio histórico e cultural, mas, também, no sentido de anular atos lesivos praticados por entes estatais. A respeito de tal entendimento, posiciona: “Afinal de contas, as referidas entidades - que constituem latíssimo sensu, a administração pública- existem para atender, direta ou indiretamente, aos interesses da sociedade, e os bens que compõem seu patrimônio estão ali afetados para servir à mesma finalidade" (ZAVASCKI, 2017, p. 86).

Em suma, no que pese o estudo da pesquisa em tela, a legitimidade processual ativa do cidadão em propor a ação popular aduz o tratamento jurídico-legal reiterado pela Constituição de 1988, pela qual garante ao cidadão um instrumento hábil da fiscalização e do controle dos atos estatais. Em linhas gerais, nas palavras do Professor Fabricio Veiga Costa: "O texto constitucional vigente atribuiu aos direitos difusos e coletivos o status jurídico de Direitos Fundamentais em virtude do seu caráter imaterial, indisponível e irrenunciável" (2012, p. 118).

Nesse mesmo viés, Juliana Maria Matos Ferreira, expõe o seguinte pensamento: “A legitimação do cidadão limita-se, desta feita, à ação popular, sendo que as demais legislações referentes ao processo coletivo "definem" quais são os legitimados ativos para a defesa dos respectivos objetos tutelados em juízo" (2017, p. 81). Com base nesses pensamentos, é possível afirmar que a legitimidade ativa do cidadão na propositura da ação popular opera por força da lei, sendo, portanto, uma garantia isolada no processo coletivo, visto que as demais ações não estão em seu polo ativo, o cidadão.

Portanto, para que de fato seja efetivado o princípio da participação, o Estado Democrático de Direito e, ainda, objetivando trazer clara a ideia da construção participada das ações pelos seus legítimos interessados, quais sejam, os cidadãos, tal apreciação precisará ser pauta de maiores debates, pois só assim o instrumento democrático se realizará.

Por essa razão, pode-se concluir que se todas as ações coletivas não constituírem, assim como a ação popular, o cidadão como legitimado ativo em sua postulação, não obsta que uma apreciação nesse sentido possa ser reivindicada ao texto constitucional. 


\section{Microssistema Brasileiro de Processo Coletivo: movimentos e anteprojetos de} codificação do direito processual coletivo no Brasil.

Existem várias espécies de agrupamento das normas no mundo jurídico. Para adentrar aos estudos do microssistema de processo coletivo, bem como às reflexões sobre a codificação das regras processuais coletivas, insta pontuar essas diferentes espécies de reunião das normas. Tem-se, portanto, a consolidação de leis, que recolhe normas esparsas e as reune de maneira sistematizada, como exemplo, a CLT. Diferentemente, a complilação de leis é mais simplificada e apenas agrupa leis de determinado assunto.

Já os códigos, possuem características mais complexa e conforme Júlio Camargo de Azevedo (2011, p. 481): “Talvez, a característica de maior importância dos Códigos diga respeito ao seu conteúdo valorativo (ou principiológico), o qual permite que todas as normas criadas para tutelar determinada matéria persigam, desde o seu nascimento, a finalidades previamente instituídas". Nesse sentido, surge o movimento da "descodificação", que ilustram um cenário de inovação no manejo das necessidades de mudança no dia-a-dia do cenário jurídico, que busca adaptar e flexibilizar as normas.

Assim, nas palavras de Júlio Camargo de Azevedo (2011, p. 481), surgem: “Os microssistemas legais, os estatutos processuais, bem como os códigos setorizados, diplomas que, ao revés de se enclausurarem em suas próprias normas, admitem o diálogo com regras exteriores, maleabilizando o uso de seu procedimento às vicissitudes do litígio entre as partes".

Todavia, deve-se ater ao aspecto valorativo existente na essência codificadora, que auxilia na construção principiológica da construção de um sistema jurídico sustentado em vieses robustos que lhe conferem a sustentação necessária para sua aplicabilidade. Ou seja, de acordo com o pensamento de José Isaac Pilati (2007, p. 166): “O Direito não é visto como composto somente de normas, mas, também, de valores e princípios jurídicos, em sistema aberto, incompleto e móvel, em que as fontes dialogam em torno de valores fundamentais, permitindo a permeabilidade com o meio social".

O microssistema de processo coletivo pode ser compreendido como o mais complexo do ordenamento jurídico brasileiro, isso porque, conforme leciona Júlio Camargo de Azevedo (2011, p. 483): "Nota-se, que sua formação é composta pela reunião intercomunicante de diversos diplomas legais, dos mais variados ramos do direito, e não só por influência de 
normas gerais".

Como já mencionado, o microssistema de processo coletivo se estrutura, essencialmente, a partir da Lei de Ação Civil Pública e do Código de Defesa do Consumidor. Ainda, nas palavras de Júlio Camargo de Azevedo (2001, p. 484): “Ambas estas leis formam o núcleo, o centro valorativo do microssistema de processo coletivo, pois [...] irradiam aplicabilidade a todos os outros diplomas legislativos que compõe o microssistema”.

Pois bem, a partir dessas análises e colocações a respeito do processo de descodificação e a relação existente no direito brasileiro, em que pese a problemática da sistematização de um Código de Processo Coletivo, a pesquisa adentra nos movimentos e anteprojetos propostos que alçaram estudos pertinentes sobre a relevância do tema em estudo.

$\mathrm{Na}$ década de 80 e 90, alguns pesquisadores como Gregório Assagra, Nelson Nery Junior, Antonio Gidi, Ada Pelegrini Grinover, Vicente de Paula Maciel Junior e José Carlos Barbosa Moreira, tomaram um estudo a fim de esclarecer inúmeros pontos no sentido de analisar o objeto do processo coletivo, qual seja, sua legitimação compatível ao Estado Democrático de Direito, elencado na Constituição de 1988.

Foi a partir da implantação da Lei de Ação Civil Pública, do Código de Defesa do Consumidor e, também, da Constituição brasileira de 1988, que o movimento de criação de um Código de Processo Civil Coletivo se fortificou.

O professor Fabricio Veiga Costa, esclarece que: "Por volta de 2002, o jurista brasileiro Antônio Gidi finalizou o que hoje se denomina de "Primeiro Anteprojeto de um código de Processo Civil Coletivo", ora denominado de Anteprojeto Original, iniciado em 1993 e finalizado em 2002" (2012, p. 133).

O segundo anteprojeto é do Código Modelo de Processos Coletivos do Instituto Ibero-Americano de Direito Processual, que fora iniciado em 2002, onde ficou estabelecido que um projeto de um Código de Processo Civil Coletivo Modelo seria elaborado em conjunto pelo Centro de Estudos Jurídicos Latino-americanos e o Instituto Ibero-Americano de Direito Processual.

O terceiro Anteprojeto foi elaborado em 2005, e desenvolvido na Universidade do Estado do Rio de Janeiro e da Universidade Estácio de Sá. O quarto anteprojeto teve sua iniciação em 2003 e foi finalizado em 2007, na Universidade de São Paulo. 
Todas as pesquisas ${ }^{3}$ introduzidas como continuidade ao Anteprojeto Original de Antonio Gidi demonstra, ainda, o vulto da construção dada pela obra de Juliana Maria Matos Ferreira, no aspecto de trazer o cidadão para o rol dos legitimados para a propositura das ações coletivas, em especial a ação civil pública, que como já fora mencionado, traz um rol taxativo, excluindo o cidadão: "Fundamental asseverar que o projeto em referência amplia o rol dos legitimados, acrescentando a legitimação do cidadão para a defesa dos interesses ou direitos difusos de que seja titular um grupo, categoria ou classe de pessoas ligadas por circunstâncias de fato (2017, p. 118).

A essencial denotação que aqui se busca inserir diante dos estudos da formação participada direta do mérito pelo interessado no processo coletivo, e a preocupação que se demonstra o Brasil em elaborar e propor um anteprojeto de lei que busque sedimentar o Código de Processo Coletivo Brasileiro, fez com que o Ministro de Estado da Justiça, em 2008, publicasse a Portaria $\mathrm{n}^{\mathrm{o}}$ 2481, que constutuiu uma Comissão Especial composta por juristas, especialistas, membros da Magistratura, Ministério Público, Defensoria Pública e Advocacia com o objetivo de analisar e elaborar proposta de aprimoramento e modernização da legislação material e processual que trate direitos coletivos, difusos e metaindividuais homogêneos, de forma a subsidiar o Ministério da Justiça e órgãos do Governo Federal, contemplando os anteprojetos do Código Brasileiro de Processo Coletivo, Código Modelo de Processos Coletivos para Ibero América e outras proposições em debate no meio acadêmico e profissional.

Dos trabalhos dessa Comissão", bem como " do Ministério da Justiça, foi desenvolvido e apresentado pelo Governo Federal, o Projeto de Lei $n^{\circ}$ 5139/2009, que

\footnotetext{
${ }^{3}$ As referidas pesquisas tiveram como consequência a elaboração de várias obras em processo coletivo, dentre elas citamos as seguintes: Direito Processual Coletivo e o Anteprojeto de Código Brasileiro de Processos Coletivos, sob a coordenação de Ada Pelegrini Grinover, Aluisio Gonçalves de Castro Mendes e Kazuo Watanabe. (FERREIRA, 2017, p. 117).

${ }^{4}$ Segundo o art. $2^{\circ}$ da citada Portaria, compõem a Comissão: I - Rogerio Favreto, Secretário de Reforma do Judiciário, do Ministério da Justiça, que a presidirá; II - Luiz Manoel Gomes Junior, como relator; III - Ada Pellegrini Grinover; IV - Alexandre Lipp João; V - Aluisio Gonçalves de Castro Mendes; VI - André da Silva Ordacgy; VII - Anizio Pires Gavião Filho; VIII - Antonio Augusto de Aras; IX - Antonio Carlos Oliveira Gidi; X - Athos Gusmão Carneiro; XI - Consuelo Yatsuda Moromizato Yoshida; XII - Elton Venturi; XIII Fernando da Fonseca Gajardoni; XIV - Gregório Assagra de Almeida; XV - Haman Tabosa de Moraes e Córdova; XVI - João Ricardo dos Santos Costa; XVII - José Adonis Callou de Araújo Sá; XVIII - José Augusto Garcia de Souza; XIX - Luiz Philippe Vieira de Mello Filho; XX - Luiz Rodrigues Wambier; XXI Petronio Calmon Filho; XXII - Ricardo de Barros Leonel; XXIII - Ricardo Pippi Schmidt; XXIV - Sergio Cruz Arenhart. (Câmara dos Deputados Projeto de lei n. ${ }^{\circ}$ 5.139, de 2009 do Poder Executivo. Mensagem no 238/2009, Aviso no 214/2009 - C. Civil, Portaria n 2.481, de 9 de dezembro de 2008, p. 53-54).
} 
disciplina a ação civil pública para a tutela de interesses difusos, coletivos ou individuais homogêneos" (FERES, 2009, p. 72).

Nota-se, portanto, que para a efetivação de um Código de Processo Civil Coletivo pautado no que disciplina a Constituição Brasileira de 1988, ou seja, compatível com o Estado Democrático de Direito, vislumbra uma nova construção da Teoria Geral do Processo, este pelo qual está vinculado em um sistema individualista de legitimados para propositura da ação, com forte influência no sistema representativo, o que vai à contramão da ideia desta pesquisa, pois esta tem como fulcro a legitimação participada do processo coletivo.

Apesar de ser apoiador da codificação do processo coletivo, Gregório Assagra de Almeida expõe em sua obra alguns pontos negativos, são eles:

\begin{abstract}
A possibilidade de engessamento do sistema; mitigação de conquista com retrocessos indevidos no plano dos avanços já obtidos no sistema pátrio tanto no plano constitucional quanto no plano infraconstitucional; a adoção de modelos estrangeiros incompatíveis com o sistema brasileiro; à burocratização do próprio sistema do direito processual coletivo, com a geração de incidentes indesejáveis que venham retardar a tutela jurisdicional coletiva com prejuízos aos interesses sociais; a vinculação com a concepção liberal individualista do CPC, o que poderá ocorrer com a elaboração de um código que não rompa com as amarras do referido diploma processual etc. (2007, p. 83-84).
\end{abstract}

Nessa perspectiva, observa-se os pontos que se fazem pertinentes trazer para que sirvam de objeto de análise e crítica a partir dos estudos propostos pelos juristas.

Tais debates são alçados em inúmeros trabalhos científicos e circundam através de questionamentos acerca da necessidade ou não da codificação do processo coletivo. Evidente que existem os que defendem a necessidade da codificação e outros que entendem como não necessária. Aos defensores da codificação, como por exemplo: Ada Pellegrini Grinover, Gregório Assagra de Almeida, Aluísio Gonçalves de Castro Mendes, Rodolfo de Camargo Mancuso, em que, se sustenta por meio do seguinte argumento, trazido pelas palavras de Júlio Camargo de Azevedo (2011, p. 489): “A necessidade de ordenação e uniformização do sistema coletivo, onde a delimitação da abrangência da tutela coletiva poderia evitar entendimentos contraditórios".

Contudo, é sabido que a preocupação da sistematização de um Código de Processo Coletivo se baseia em aspectos procedimentais que buscam efetivar e garantir que de fato as demandas sejam vistas sob o olhar democratizado, se afastando dos resquícios autoritários trazidos pelo Código de Processo Civil, cujo objetivo é sistematizar formas e meios de resolução de conflitos de interesses individuais. Parte da doutrina que se opõe à codificação, 
explica que "o sistema jurídico coletivo ainda não estaria — maduro o suficiente para prever um código completo de direitos coletivos, dada sua recente aparição no direito brasileiro" (AVEVEDO, 2011, p. 490).

Ademais, o que se pretende aqui é justamente apontar a justa necessidade de afastar os resquícios tradicionais do processo individual, que foram implementados ao microssistema de processo coletivo e comprometem a formulação de um verdadeiro Código de Processo Coletivo, visto a problemática de legitimação que traz a procedimentalização do processo civil.

A construção das premissas teóricas, voltadas à sistematização e codificação do processo coletivo democrático, fundam-se na necessidade de reconhecer o protagonismo dos interessados difusos e coletivos como atores que participam diretamente da construção do provimento final de mérito. Para isso, torna-se imprescindível romper com as amarras do sistema representativo, cujo pilar adotado pelo legislador infraconstitucional foi conferir legitimidade a determinadas instituições, destinadas a representar a coletividade, sem condicionar o julgamento do mérito da pretensão deduzida à realização de audiências públicas que garantam a participação dos interessados.

A opção pelo sistema participativo representa simbolicamente a aderência às premissas trazidas pelo texto da Constituição brasileira de 1988. O processo coletivo democrático tem como pilar o reconhecimento do direito de todos os interessados difusos e coletivos poderem participar amplamente do debate das questões controversas que integram o mérito da pretensão coletiva. Mesmo que o cidadão não tenha legitimidade processual ativa, sua legitimação para participar do debate do mérito processual e das questões controversas da demanda é decorrente da interpretação sistemático-integrativa do texto constitucional.

\section{Conclusão}

A presente pesquisa não se aprofundou na ampla discussão de todas as perspectivas realizadas a partir dos movimentos e anteprojetos propostos para a codificação processual coletiva, visto que a análise se restringiu à problemática de legitimação dos interessados difusos e coletivos em torno dos direitos transindividuais. Quando se fala em direitos difusos e coletivos a preocupação legislativa se atine em promover uma ampla discussão acerca dos 
seus legitimados, na intenção de garantir o acesso à jurisdição de forma democratizada e a partir de uma sistemática meritória que garanta aos interessados o protagonismo na construção dialética do provimento final de mérito.

Nesse sentido, a pesquisa vem concorrer para a busca de uma verdadeira autonomia do bem jurídico sob a titularidade dos indivíduos que de fato são atingidos pelos efeitos jurídicos da decisão final de mérito proferida, ou seja, se o titular do direito é a coletividade, não obsta ser representado pelo Estado, mas sim que seja ouvido de forma a garantir o direito à sua dignidade e na esfera de proteção constitucional da segurança jurídica.

O processo coletivo democrático-constitucionalizado funda-se na premissa por meio da qual deve-se assegurar a todos os interessados difusos e coletivos o direito de igual participação na formação do mérito. O provimento final de uma ação coletiva deve ser reflexo de amplo debate plebiscitário, que torne viável a direta participação de todos os interessados na sua construção dialética da decisão final de mérito, ressignificando o protagonismo e a discricionariedade judicial. É nesse contexto que se torna necessária a proposição de uma teoria geral do processo coletivo, codificado em bases constitucionais, democráticas, que privilegiam o sistema participativo e, assim, garanta o igual direito conferido a todos os interessados de poderem participar da construção do provimento final de mérito.

É sabido que as pretensões coletivas vão de encontro e causam desconforto aos setores político-econômicos nacionais, visto que as grandes indústrias e instituições financeiras brasileiras atuam em detrimento da busca pela codificação dessas ações, vez que são essas ações que buscam a efetivação de políticas fiscalizadoras e atribuem sentido ao processo coletivo que visa defender princípios democráticos.

$\mathrm{Na}$ presente pesquisa foi demonstrado que o coletivo deve ter o mesmo espaço que o processo civil concedeu ao individual, ou seja, definir o processo coletivo brasileiro sob a ótica de um modelo democrático-participativo, garantindo-se a paridade a todos os interessados quanto à formação participada do mérito e a construção dialética do provimento final.

Os princípios constitucionais balizadores do direito público, em concomitância com as garantias e direitos fundamentais trazidos pela Constituição de 1.988, deságua neste trabalho através dos estudos trazidos pela constitucionalização do processo. O modelo constitucional do processo e o Estado Democrático de Direito são peças fundamentais para o 
diálogo das demandas coletivas, esquivando-se do modelo individualista na qual se herdou dos códigos anteriores.

Nesse sentido, foi discutido duas ações, quais sejam: a ação civil pública e a ação popular, sendo que esta tem o cidadão como figura ativa em sua propositura, ao passo que a primeira excluiu o cidadão do rol de legitimados para tanto. Observou-se, portanto, a adoção do sistema representativo na ação civil pública, ou seja, o modelo legislativo adotado no Brasil afasta a manifestação direta dos indivíduos, ocasionando um rompimento com os princípios constitucionais que, de fato, materializa o exercício da democracia.

Contudo, existem vários estudos e discussões em que pese à elaboração de um Código Brasileiro de Processo Coletivo, na intenção de romper com os laços individualistas trazidos pelo antigo código de processo civil.

Nessa perspectiva, nasce a ideia de um processo coletivo democrático sob a ótica de um sistema participativo, visto que o indivíduo figura ativamente nas demandas em que ele tem interesse legítimo. O sistema participativo vem contemplar os princípios constitucionais da soberania e da participação popular, conduzindo, assim, ao Estado Democrático de Direito. Assim, tem-se que todos os interessados que serão atingidos pela decisão meritória devem ser legitimados a participar e, juntos, serão fortalecidos em construir uma melhor solução para a demanda que os atingirá a partir do provimento jurisdicional.

A esperança na elaboração de um Código Brasileiro de Processo Coletivo que represente de fato uma efetivação de garantia de acesso à jurisdição, no sentido precípuo de efetividade na prestação jurisdicional das demandas coletivas, se faz pertinente aos estudos que foram aqui expostos, pois é a partir desses debates que será construída uma sistematização sólida e garantidora dos direitos coletivos e difusos no Estado Democrático de Direito.

Do que fora exposto, em sede de considerações finais, insta claro que os debates aqui trazidos são de importante valoração a partir da necessidade de criação de um sistema de processo coletivo único que regule a tutela coletiva. A ausência de tratamento específico leva os direitos transindividuais a dependência de procedimentos processuais que se alinham ao processo individual, o que, muitas vezes o coloca em divergências e prejudica a prestação equânime dos direitos coletivos. 
Para além, a fim de que seja possível uma provável sistematização e, assim, a criação do Código de Processo Coletivo Brasileiro, torna-se necessário uma maior compreensão dos representantes do poder Legislativo, em que pese sua atuação em favor dos interesses do povo e não a favor de interesses de grupos privados. Esse resquício autocrático dos sistemas políticos são barreiras que impedem a ampliação de forca normativa tendente em garantir direitos fundamentais a partir das ações coletivas.

\section{Referências}

ALMEIDA, Gregório de Assagra. Codificação do direito processual coletivo brasileiro: análise crítica das propostas existentes e diretrizes para uma nova proposta de codificação. Belo Horizonte: Del Rey, 2007.

AZEVEDO, Júlio Camargo de. O microssistema de processo coletivo brasileiro (uma análise feita à luz das tendências codificadoras). Revista Eletrônica de Direito Processual - REDP. Volume VIII. ISSN 1982-7636. Periódico da Pós-Graduação Stricto Sensu em Direito Processual da UERJ. Disponível em: https://www.epublicacoes.uerj.br/index.php/redp/article/view/20831/15109 . Acesso em: 10 dez. 2020.

BINENBOJM, Gustavo. A nova jurisdição constitucional: legitimidade democrática e instrumentos de realização. 4. ed. rev., ampl. e atual. Rio de Janeiro: Renovar, 2014.

BONAVIDES, Paulo. Curso de direito constitucional. 10. ed. rev., atual. e ampl. São Paulo: Malheiros, 2000.

BRASIL. Constituição da República dos Estados Unidos do Brasil. Rio de Janeiro: Casa Civil, Subchefia para Assuntos Jurídicos, 1934. Disponível em: http://www.planalto.gov.br/ccivil_03/Constituicao/Constituicao34.htm. Acesso em: 03 fev. 2021.

BRASIL. Constituição da República dos Estados Unidos do Brasil. Rio de Janeiro: Casa Civil, Subchefia para Assuntos Jurídicos, 1946. Disponível em:

http://www.planalto.gov.br/ccivil_03/Constituicao/Constituicao46.htm. Acesso em: 03 fev. 2021.

BRASIL. Constituição da República Federativa do Brasil. Brasília: Casa Civil, Subchefia para Assuntos Jurídicos, 1988. Disponível em:

http://www.planalto.gov.br/ccivil_03/constituicao/constituicaocompilado.htm. Acesso em: 03 fev. 2021.

BRASIL. Emenda Constitucional No 1. Brasília: Casa Civil, Subchefia para Assuntos Jurídicos, 1946. Disponível em: 
http://www.planalto.gov.br/ccivil_03/Constituicao/Emendas/Emc_anterior1988/emc0169.htm. Acesso em: 03 fev. 2021.

BRASIL. Lei no 4.717, de 29 de junho de 1965. Brasília: Casa Civil, Subchefia para Assuntos Jurídicos, 1965. Disponível em:

http://www.planalto.gov.br/ccivil_03/leis/L4717.htm. Acesso em: 03 fev. 2021.

BRASIL. Lei no 7.347, de 24 de julho de 1985. Brasília: Casa Civil, Subchefia para Assuntos Jurídicos, 1985. Disponível em: http://www.planalto.gov.br/ccivil_03/leis/L7347orig.htm. Acesso em: 03 fev. 2021.

BRASIL. Câmara dos Deputados. Projeto de Lei n. 5.139, de 2009 (do Poder Executivo). Disponível em:

https://www.camara.leg.br/proposicoesWeb/prop_mostrarintegra;jsessionid=6035F632AD4B 9F6A7E187E0B3B733F23.proposicoesWebExterno2? codteor $=761353 \&$ filename $=$ Avulso $\% 2$ 0-PL\%205139/2009. Acesso em: 11 dez. 2020.

COSTA, Fabrício Veiga. Mérito processual: a formação participada nas ações coletivas. Belo Horizonte: Arraes Editores, 2012.

CARVAS, FELIPE. Cadastro Nacional de Ações Coletivas. 2009. 28 f. Artigo - (Mestrado em Direito das Relações Sociais, Direitos Difusos e Coletivos) - PUC-SP, São Paulo, 2009. Disponível em:

https://www.pucsp.br/tutelacoletiva/download/cadastro_nacional_pessoas_coletivas.pdf. Acesso em: 22 maio 2021.

FERREIRA, Juliana Maria Matos. Teoria do processo coletivo no modelo participativo. Belo Horizonte: Editora D’Plácido, 2017.

FERREIRA, Juliana Maria Matos. O modelo participativo de processo coletivo: as ações coletivas como ações temáticas. 2009. 190 f. Dissertação - (Mestrado em Direito) - Pontifícia Universidade Católica de Minas Gerais, Belo Horizonte, 2009. Disponível em: http://www.biblioteca.pucminas.br/teses/Direito_UrsineIM_1r.pdf. Acesso em 03 mar. 2021.

FERES, Josan Mendes. A formação do objeto nas ações coletivas sob a perspectiva das ações temáticas: a participação direta dos interessados. 2009. 166 f. Dissertação- (Mestrado em Direito) - Pontifícia Universidade Católica de Minas Gerais, Belo Horizonte, 2009.

Disponível em: http://www.biblioteca.pucminas.br/teses/Direito_FeresJM_1.pdf. Acesso em: 03 mar. 2021.

GOMES JUNIOR, Luiz Manoel; FAVRETO, Rogerio. O projeto da nova lei da ação civil pública: aspectos principais. Revista Internacional de Estudios sobre Derecho Procesal y Arbitraje, Madrid, abr. 2010. Disponível em: file:///C:/Users/Cliente/Downloads/DialnetOProjetoDaNovaLeiDaAcaoCivilPublica-3700464\%20(2).pdf . Acesso em: 19 dez. 2020.

MACIEL JUNIOR, Vicente de Paula. Teoria das ações coletivas: as ações coletivas como ações temáticas. São Paulo: LTr, 2006. 
MENDES, Conrado Hübner. Direitos fundamentais, separação de poderes e deliberação. Tese (Doutorado em Ciência Política) - Faculdade de Filosofia, Letras e Ciências Humanas, Universidade de São Paulo, São Paulo (2008). Disponível em: http://www.teses.usp.br/teses/disponiveis/8/8131/tde-05122008-162952/pt-br.php. Acesso em:19 maio 2021.

MORAES. Alexandre de. Direito constitucional. 13. ed. São Paulo: Atlas, 2003.

OMATTI, José Emílio Medauar, 1977 - Uma teoria dos direitos fundamentais / José Emílio Medauar Omatti. 7. ed. - Belo Horizonte: Conhecimento Editora, 2020.

PILATI, José Isaac. Tutela coletiva: crítica às propostas de sua codificação processual no Brasil. Revista Sequência. no 55, p. 151-174, dez. 2007. UFSC, Florianópolis, SC, Brasil. ISSNe 2177-7055. Disponível em:

https://periodicos.ufsc.br/index.php/sequencia/article/view/15051/13721 . Acesso em: 10 dez. 2020.

SILVA, José Afonso da. O constitucionalismo brasileiro: evolução institucional. 1. ed. São Paulo: Editora Malheiros, 2011.

SOARES, Mário Lúcio Quintão. Teoria do Estado. Belo Horizonte: Del Rey, 2004, p. 219220.

ZAVASCKI, Teori Albino. Processo coletivo: tutela de direitos coletivos e tutela coletiva de direitos. 7. ed. rev., atual. e ampl. São Paulo: Editora Revista dos Tribunais, 2017.

ZANETI JR., Hermes; GARCIA, Leonardo de Medeiros. Direitos Difusos e Coletivos. 5. ed., Salvador: Juspodivm, 2014. 